\title{
Evaluation of U-Lnp' Curves for the Stabilization of Saline Clayey Soils
}

\author{
Mehrdad Haratian a, Ahad Bagherzadeh Khalkhali a, b* \\ ${ }^{a}$ Department of Civil Engineering, Science and Research Branch, Islamic Azad University, Tehran, Iran. \\ ${ }^{b}$ Department of Irrigation and Drainage Engineering, College of Aburaihan, University of Tehran, Tehran, Iran.
}

Received 20 June 2018; Accepted 13 October 2018

\begin{abstract}
Saline soils are one of the challengeable soils that can cause many problems in civil engineering designs. In this study, volume change behavior and stress path changes in the U-Lnp' space of these soils, and the effect of stabilization and reinforcement on them have been investigated. Case study of this research is Amirkabir Highway between Qom and Kashan. In 54th Km of this highway, road surface is distorted and it is observed that its soil is saline clay in field investigation; and considering surface flow of water in that place, it is induced that, probably, the presence of water causes such a condition. For this purpose, after sampling and conducting preliminary experiments such as particle size analysis, Atterberg limits and compaction, first of all, the soil of considered place was examined by swelling potential and consolidation tests. as a result, volume change behavior parameters of undisturbed and disturbed soils have been determined and it was specified that disturbed soil has a considerable swelling potential. Then swelling potential and consolidation tests have been conducted on stabilized samples with different amount and curing time of lime, epoxy - resin polymer and also reinforced samples with different amount of polypropylene fiber; moreover, their results for two cases of stabilized and non-stabilized samples have been compared. According to the results of the consolidation experiments and the potential for swelling, it is observed that the impaction strongly affects the volume behavior and the soil stress path. The comparison among swelling parameters (free swelling and swelling pressure) of stabilized samples with polymer and lime and reinforced samples with polypropylene fiber showed that all of these materials reduce free swelling, but for the case of swelling pressure, with $9 \%$ of polymer swelling pressure increases and for other cases this pressure decreases, that this issue is one of disadvantages of polymer stabilization. The results obtained from the consolidation test indicate that the slope of the normal consolidation line $\lambda$ and the swell line slope $\kappa$ in the stabilized samples are smaller than the unstabilized samples.
\end{abstract}

Keywords: Saline Clayey Soil; Volume Change Behavior; Stress Path in the U-Lnp' Space; Swelling; Consolidation; Stabilization; Lime; Epoxy -Resin Polymer; Polypropylene Fiber.

\section{Introduction}

Considering that nearly 15 percent of Iran's territory is covered with saline soils, there is little study in the field of soil mechanic parameters and studies done limited to agricultural and geological fields, as well as considering the problems that these soils cause for development projects, the geotechnical characteristics of these soils are studied and a solution for improvement is provided.

Saline soils are one of challengeable soils that could cause many problems in civil engineering designs. Many studies have been conducted for determining geotechnical properties of saline soils all over the world. Sabkha soils are one of saline soils that much researches has been done into them [1,2]. Main features of saline soils are high compressibility

* Corresponding author: a.bagherzadehkh@ut.ac.ir

http://dx.doi.org/10.28991/cej-03091169

> This is an open access article under the CC-BY license (https://creativecommons.org/licenses/by/4.0/).

(C) Authors retain all copyrights. 
and low bearing capacity. One of their main defects is swelling capability that is a general problem everywhere. Considering sudden development of urban area and also highways and road networks between cities, civil engineers have to construct significant plans over them. For the first time, in 1938, U.S Earth Reform Bureau introduced soil swelling from soil mechanic's point of view. Since that time, civil engineers have been awarded that main cause of destruction could be something except settlement [3]. Dangers stem from expansive soils in civil structures (buildings, roads, superstructure, light Dali foundation and other light constructs from loading point of view) have been reported all over the world [4]. Estimated damages by the effects of these soils exceed billion dollars annually [5, 6]. Nevertheless, a few researches have been done into stabilization and reinforcement or improvement of these soils. For the case of Sabkha soil, the effect of geo-textile and cement on these soils with the aim of increasing bearing capacity of superstructures has been investigated [7, 8]. Because vast part of Iran is covered by saline soils and their mentioned problems, and some plans especially road accomplishment of construction some of structures are constructed over these indispensable soils, our effort in this study is firstly to investigate volume change behavior and thereafter improvement of swelling properties of these soils via stabilization and reinforcement.

The case study of this paper is considered based on the problem in 54th $\mathrm{Km}$ of Amir Kabir Highway that is located between Qom and Kashan cities. In this part of highway, the surface of the road has been distorted (wave-like). By field investigation, it was specified that soil texture is composed of saline soils and surface flow of water has been induced by swelling of the road.

\section{Location of the Place}

The case study of this research is located in 54th Km of Amir Kabir Highway that is located between Qom and Kashan cities. In this part of highway, surface of the road is distorted. Considering several repairs of road's surface, it was observed that over time (a few months) and by commence of the spring season ruffled undulant appeared in the surface of the road. By field investigation, it was specified that soil texture is composed of saline soils and also surface flow of seasonal water exists at that part of highway. Figure 1 shows the salinity of local soils. After preliminary studies and field investigation, soil of this place was selected for this research.

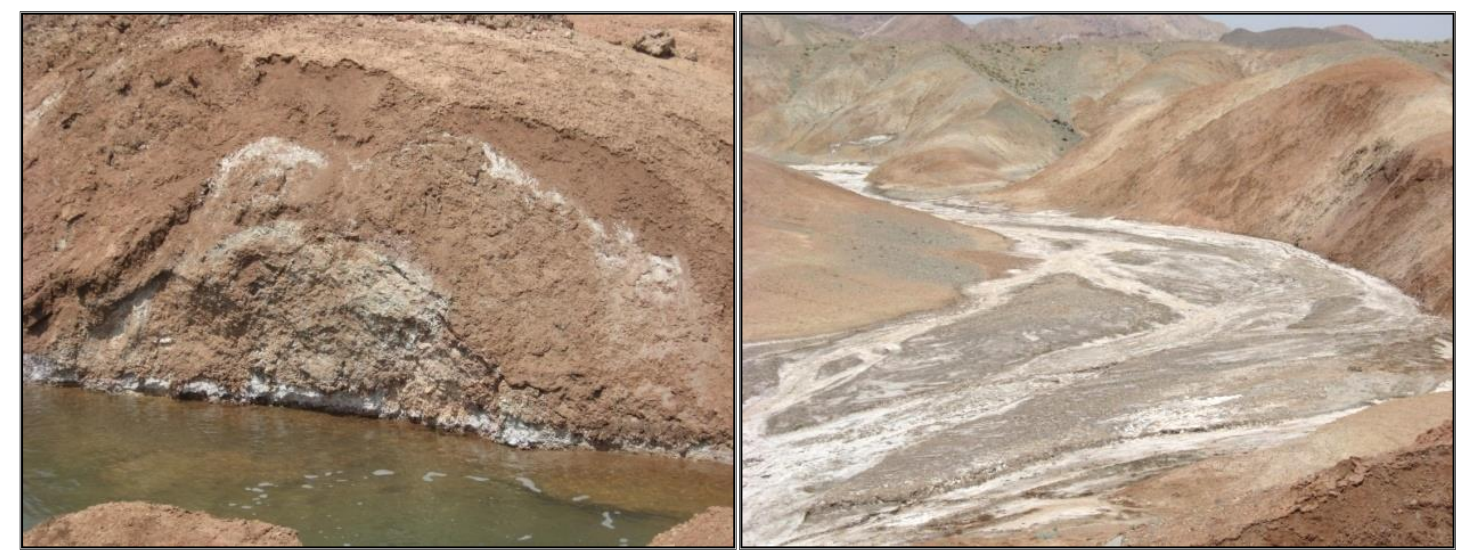

Figure 1. Mentioned area and salinity of local soil surface

\section{Sampling and in-Situ Tests}

After initial studies, field investigation and site selection, disturbed and undisturbed sampling are implemented by drilling two Test pit with the height of $2.5 \mathrm{~m}$ and also some tests like in-situ density and SPT have been conducted and their results have been tabulated in Table 1.

Table 1. Results of in - situ tests

\begin{tabular}{cccc}
\hline $\begin{array}{c}\text { Wet density } \\
\mathbf{g r}^{\mathbf{c}} \mathbf{c m}^{\mathbf{3}}\end{array}$ & $\begin{array}{c}\text { Dry unit weight } \\
\mathbf{g r} / \mathbf{c m}^{\mathbf{3}}\end{array}$ & $\begin{array}{c}\text { Moisture content } \\
\boldsymbol{\%}\end{array}$ & NSPT \\
\hline 2.12 & 1.86 & 16.5 & 39 \\
\hline
\end{tabular}

Studied soil is saline clayey soil [9]. After sampling from selected site, preliminary tests such as particle size analysis, hydrometry, Atterberg limits and soil chemistry have been done. Mentioned soil was classified as clay with low plastic property i.e. CL. Other properties are listed in Table 2 and particle size distribution curve is shown in Figure 2. 
Table 2. Properties of studied soil

\begin{tabular}{cccccccc}
\hline $\mathbf{G}_{\mathbf{s}}$ & $\mathbf{L L}$ & $\mathbf{P L}$ & $\mathbf{P I}$ & USCS Classification & PH & EC* & TDS** \\
\hline 2.73 & 41 & 22 & 19 & $\mathrm{CL}$ & 7.80 & 83.38 & 8.02 \\
\hline
\end{tabular}

* Electrical Conductivity

** Total Dissolved Salt

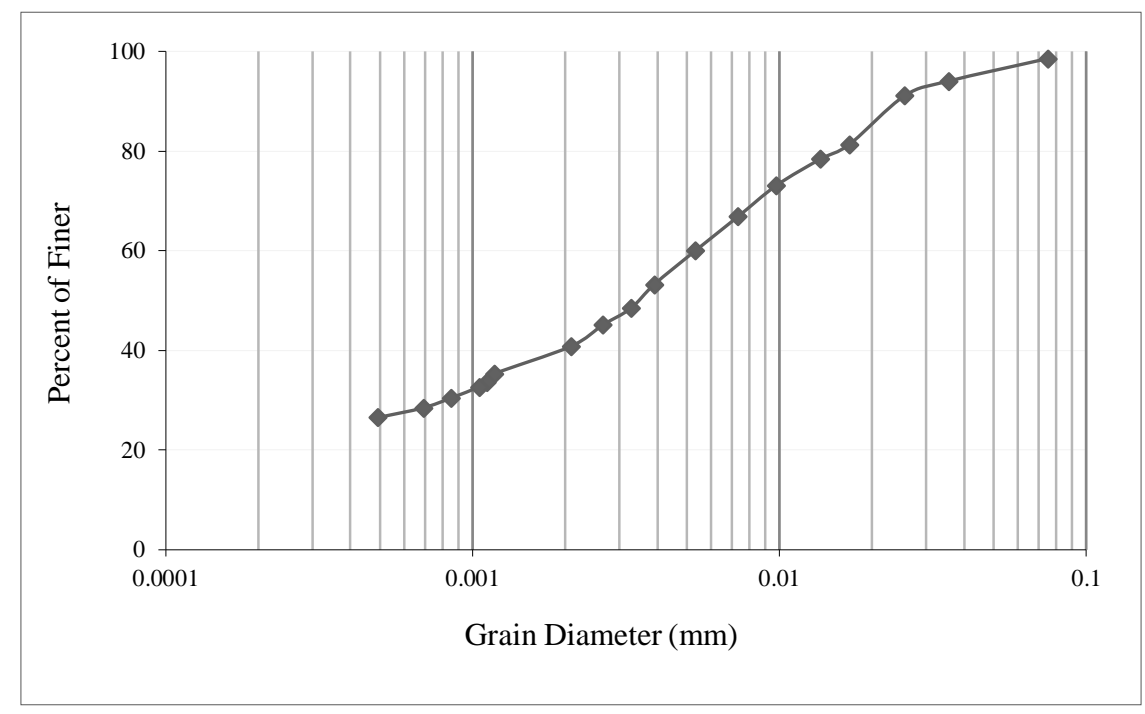

Figure 2. Particle size distribution curve

\section{Characteristics of Applied Stabilizers and Reinforcement Agents}

Among traditional stabilizers, since lime is selected as a suitable stabilizer in previous studies for stabilizing saline and swelling clayey soils [10-14], and among non-traditional stabilizers polymers because of their more recognition and more availability, these two stabilizers are selected for our study. Polypropylene fiber was used for this study as a stabilizer that has been selected due to its compatibility with clayey soils and also its availability in Iran [15].

\subsection{Lime}

In this study, hydrated lime was used as a stabilizer. Although caustic lime, due to its high content of $\mathrm{CaO}$, has more influence on stabilizing and improvement of soil with respect to hydrated or slaked lime, it has been selected because working with hydrated lime is more safe and its application is more. Generally, $4 \%$ of hydrated lime is equivalent to 3 $\%$ of caustic lime, exceptionally, caustic lime needs more water. In comparison with slaked lime, Caustic lime has more volume change; average volume change of caustic lime relative to slaked lime is 2.5 to 3 times. In this study, used lime was hydrated lime with $\mathrm{PH}$ of 12.52 and original specific gravity of $560 \mathrm{Kg} / \mathrm{m}^{3}$ and particle density of 2.32 , and more than $90 \%$ of the lime is $\mathrm{Ca}(\mathrm{OH})_{2}$. In this study, due to special condition of soil and more effectiveness of low percent, 2-6 percent $(2,4$ and $6 \%)$ has been used for experiments.

\subsection{Polymer}

Polymer which is used in this study is from thermoses that are called resin-epoxy. Resins of epoxy that is also called epoxide resins have chemical structure that consists of two portions, one of them is epoxy and the other one is nonepoxy. Resin-epoxy that is used in this study was resin-epoxy of Bis-phenol which is the product of Bisphenol-A and Epichlorohydrin reaction.

Resin-epoxy polymer is a non-water-based polymer, and in contrast with water-based polymer that loses their strength in contact with water, this polymer is water resistant and this characteristic is one of the main reasons for selection of this polymer as a stabilizer in our research. Since saline soils, in contact to water, lose considerable strength, using water-based polymer was not feasible in this study.

In this study, polyamide was used as hardening agent; furthermore, based on previous experience [16] and small particle size of the soil, 1:0.9 ratio of polymer, as hardening agent, was considered. In Table 3, some characteristics of resin-epoxy polymer of this research have been shown. For obtaining appropriate amount of stabilizer, different weight percentages of resin-epoxy polymer were added to the soil and their results were investigated. According to the previous researches and obtained results, it was identified that using lower weight percentage of this polymer is impossible. Results showed that polymer cannot sustain soil particles in prepared samples when its weight percentage is lower than 4. Because of this fact, weight percentage of higher than $4(4,5,7$ and $9 \%)$ were used for stabilization of the soil. 
Table 3. Properties of resin-epoxy polymer [16]

\begin{tabular}{cc}
\hline Chemical compound & C3H5O $[\text { C18H19O3 }]_{\mathbf{n}} \mathbf{C 1 8 H 1 9 O 3}$ \\
\hline Density & $2.2 \mathrm{gr} / \mathrm{cm}^{3}$ \\
Elasticity module & $20 \mathrm{GPa}$ \\
Melting point & More than $200 \mathrm{C}$ \\
\hline
\end{tabular}

\subsection{Polypropylene Fiber}

The fiber which is used in this study is classified as a fiber with chemical base of polypropylene polymer. According to the previous research about soil reinforcement with polypropylene fiber, this fiber, as an economic reinforcement material, was used for improvement of mechanical properties [17]. The appearance of this fiber is shown in Figure 3.

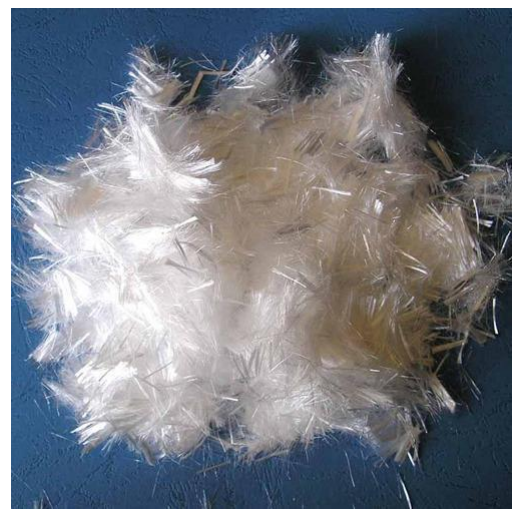

Figure 3. Polypropylene fiber used in this study

In Table 4, polypropylene fiber properties are shown. With considering literature [17], based on special condition of soil and also more effectiveness of lower weight percent, 0.1 to $0.4 \%$ of weight percentage $(0.1,0.2,0.3$ and $0.4 \%)$ were used to do the tests.

Table 4. Properties of Polypropylene fiber

\begin{tabular}{ccccccc}
\hline Melting point & Tensile strength & Diameter & Length & Specific weight & Chemical base & Appearance \\
\hline $160^{\circ} \mathrm{C}$ & $350 \mathrm{~N} / \mathrm{mm}^{2}$ & 20 micron & $14 \mathrm{~mm}$ & $900 \mathrm{Kg} / \mathrm{cm}^{3}$ & Polypropylene & White colour \\
\hline
\end{tabular}

\section{Experimental Method}

In this study, volume change behavior of disturbed, undisturbed and stabilized samples with lime and resin-epoxy polymer and also reinforced samples with polypropylene fiber were compared with each other. After doing compaction test on natural soil, this test conducted for stabilized samples with 2, 4 and 6 of lime percent and samples with $0.1,0.2$, 0.3 and $0.4 \%$ of polypropylene fiber then dry maximum density and optimal moisture content of samples obtained. These values are used for preparing undisturbed samples. Experimental method of this study is divided into 4 kinds: Atterberg limit tests, compaction, swelling potential and consolidation tests.

\subsection{Atterberg Limits Tests}

In this section, experimental results of liquid and plastic limits have been reported for stabilized soil with lime and polymer and also reinforced soil with polypropylene fiber. It is shown that, both stabilizer (lime and polymer) and polypropylene fiber as reinforcement material reduce liquid limit of soil. This fact is shown in Figure 4. As it could be observed in Figure 4, adding lime and polymer to soil reduces liquid limit more than adding polypropylene fiber. 


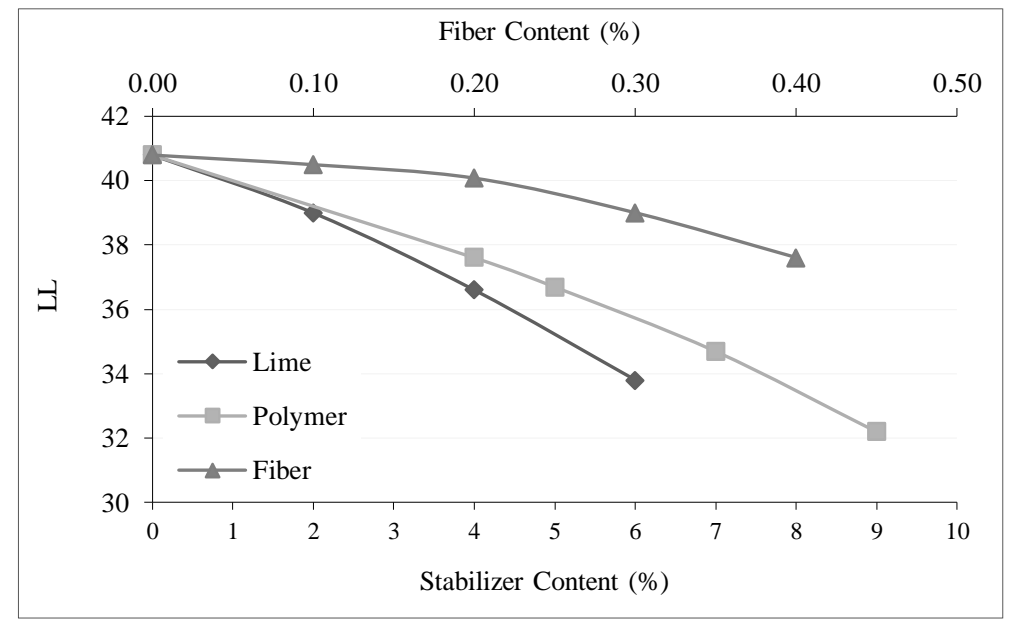

Figure 4. Influence of adding stabilizer and reinforcement material on liquid limit

Plastic limit determination test for soil and polymer mixture is impossible due to lack of wicking soil and stabilizer mixture. The result of plastic determination test for soil and lime mixture shows that adding lime increases plastic limit of the soil. As it is shown in Figure 5, variations of plastic limit of soil and polypropylene fiber mixture in comparison with soil and lime mixture is very low; therefore, plastic limit increases until it reaches $0.2 \%$ and it will decrease from $0.2-0.4 \%$. Plastic index in both mixtures has been decreased. As shown in figure 6, decrease rate of plastic index in soil and lime mixture is more than soil and polypropylene fiber mixture.

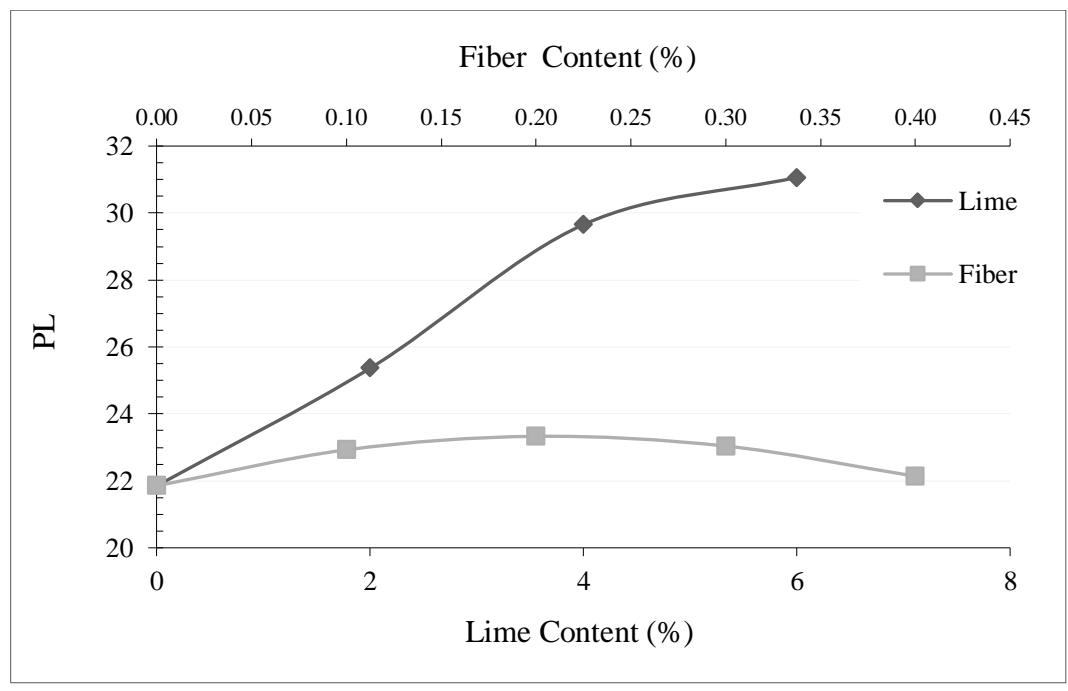

Figure 5. Effect of adding lime and polypropylene fiber on plastic limit of soil

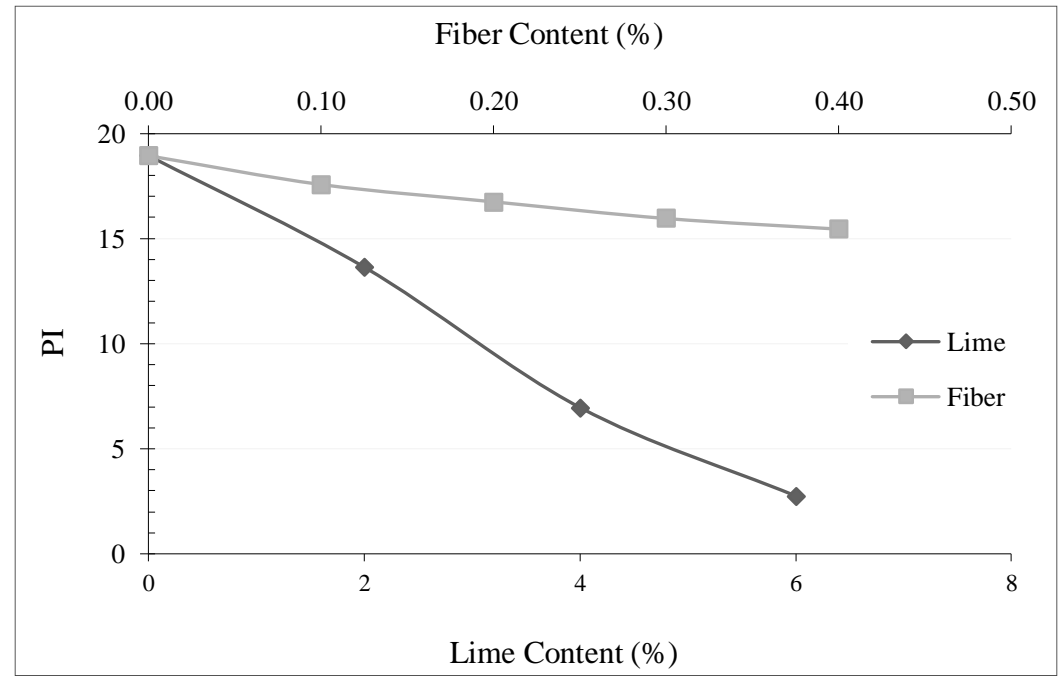

Figure 6. Effect of adding lime and polypropylene fiber on plasticity index of soil 


\subsection{Compaction Tests}

In this study, compaction test has been conducted by standard proctor method according to ASTM D698. The purpose of performing this test is to investigate compaction properties of natural soil (amount of optimal moisture content and maximum dry density) and to study adding lime and polypropylene fiber to soil.

It should be noted that, with regard to the fact that used resin epoxy polymer of this study is non-water-based polymer, and during using it, the soil should be dry. Compaction test is not possible for soil and polymer mixture, since adding water to soil and polymer mixture, and as a consequence, its compaction is impossible.

Compaction tests on natural soil and lime mixture were performed with 2, 4 and $6 \%$ of lime; and in mixture of natural soil and polypropylene fiber, the test was done with $0.1,0.2,0.3$ and $0.4 \%$ of polypropylene fiber. With regard to test results of natural soil, optimal moisture content is $18.5 \%$ and maximum dry density is $17.6 \mathrm{kN} / \mathrm{m}^{3}$. The results of compaction test on natural soil and mixture of natural soil and lime are shown as compaction curves in Figure 7.

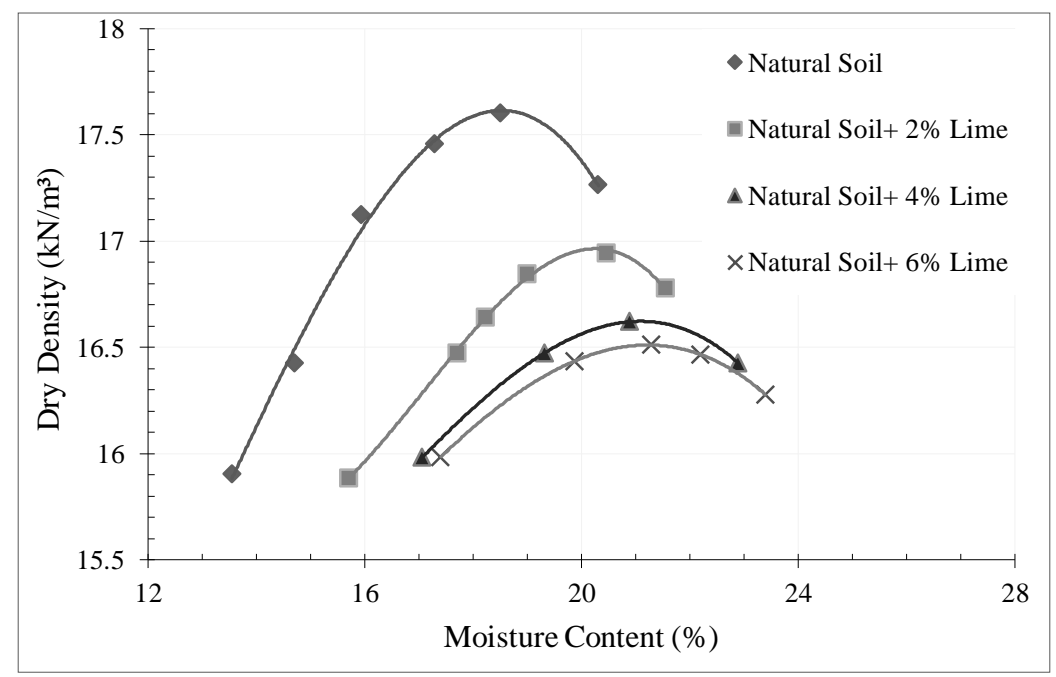

Figure 7. Compaction test results on natural soil and mixture of natural soil and lime

Results of compaction test on natural soil and mixture of natural soil and polypropylene fiber with $0.1,0.2,0.3$ and $0.4 \%$ of polypropylene fiber are shown as compaction curve in Figure 8.

According to the compaction test results, one could observe that, adding lime and polypropylene fiber to studied soil leads to the decrease of maximum dry density and increase of optimal moisture content that is ignorable in polypropylene fiber reinforced samples.

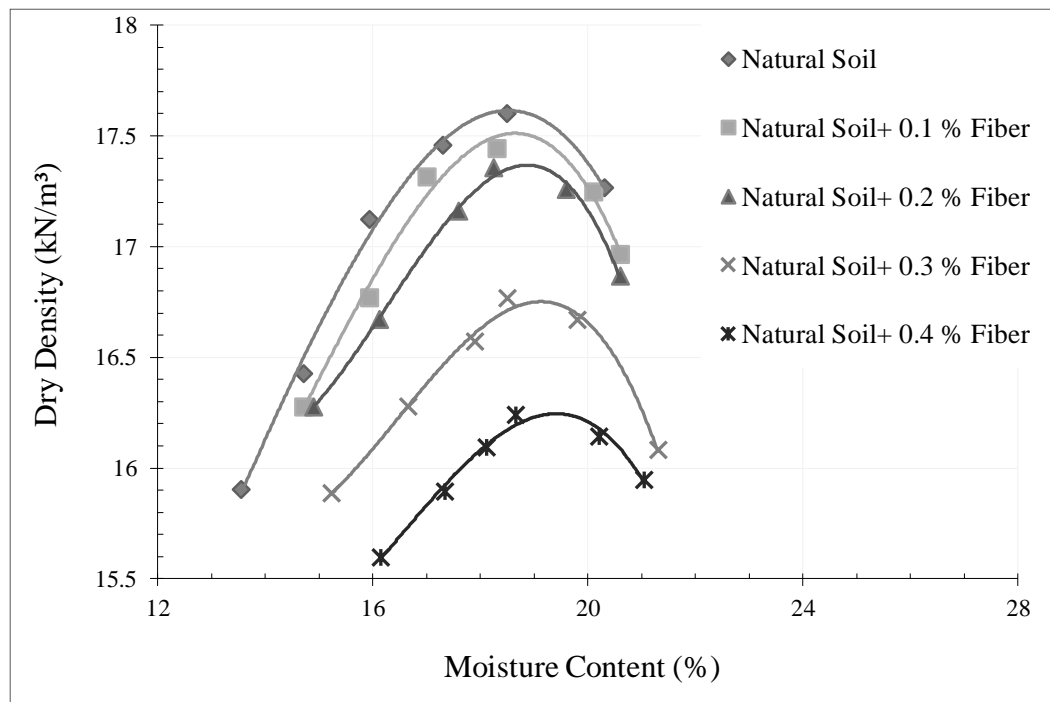

Figure 8. Results of compaction test on natural soil and mixture of natural soil and polypropylene fiber

Decrease of maximum dry density by adding lime to the soil could be as a result of higher density of soil particles $(\mathrm{Gs}=2.73)$ with respect to lime particles $(\mathrm{GL}=2.23)$. Increase of optimal moisture content could be the result of hydration and pozolaneous reaction among lime and soil and also hydrophilic characteristic of lime. By adding more lime to soil optimal moisture will increase. 


\subsection{Swelling Potential Tests}

Swelling potential tests have been done according to ASTM D4546 standard. The aim of this test is obtaining swelling parameters (free swelling and swelling pressure) which is consistent with final purpose of this study, in which, is investigating volume change parameters of saline soil and the effect of stabilization on them. Swelling potential has two parts, the first is free swelling of sample under negligible overhead pressure (about $1 \mathrm{KPa}$ ) and the second is the determination of swelling pressure.

\subsubsection{Swelling Potential Tests of Natural Soil}

After sampling and conducting preliminary tests, for free swelling test and also the determination of maximum swelling pressure, in addition to disturbed sample with regard to in situ density and moisture content and also obtained optimal moisture content and maximum dry density from test results, consolidation test of reconstructed samples was done. In Figure 9, swelling-time curve of three disturbed samples, i.e. site condition reconstructed disturbed and also reconstructed disturbed with maximum dry density and optimal moisture content is observed.

As shown in the figure, the effect of disturbance on swelling is obvious. According to obtained results of swelling tests on above-mentioned soil, one could conclude that the main cause of swelling is disturbance and destruction of initial composition and structure of the soil. This fact should be considered that, in structures such as bridges, subways and canals disturbance of soil is inevitable (this study was around a bridge location); therefore, for reducing encountered swelling, swelling potential of the soil in disturbed state has to be improved.

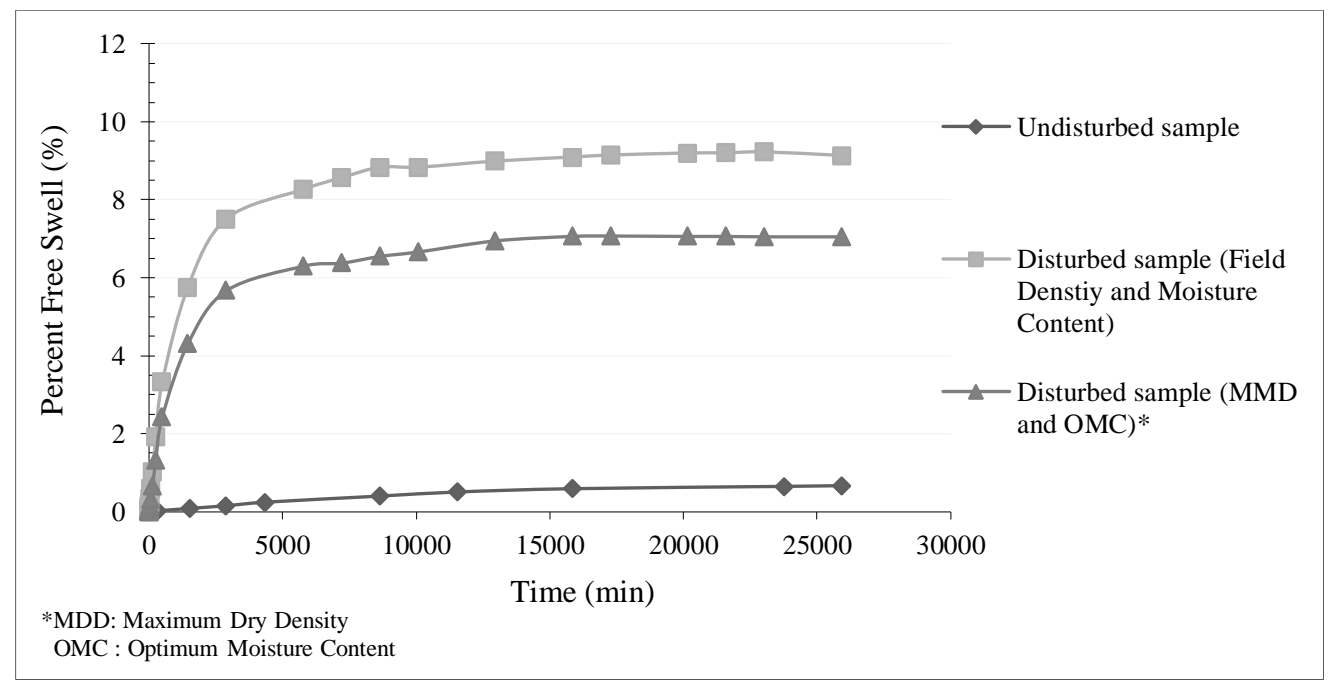

Figure 9. Swelling curve of soil with respect to time for undisturbed and disturbed samples

After the final swelling of sample, swelling pressure of undisturbed and disturbed samples was determined with odometer apparatus. Free swelling test results and swelling pressure determination of mentioned samples have been shown in Table 5.

Table 5. Swelling potential test results of undisturbed and disturbed samples

\begin{tabular}{|c|c|c|c|c|c|}
\hline Properties of soil & $\begin{array}{c}\text { Free } \\
\text { swelling } \\
(\mathbf{m m})\end{array}$ & $\begin{array}{c}\text { Free swelling } \\
(\%)\end{array}$ & $\begin{array}{l}\text { Free normalized swelling } \\
\text { with respect to disturbed } \\
\text { sample }(\%)\end{array}$ & $\begin{array}{c}\text { Swelling } \\
\text { pressure }(\mathbf{k P a})\end{array}$ & $\begin{array}{c}\text { Swelling pressure } \\
\text { with respect to } \\
\text { disturbed sample }(\%)\end{array}$ \\
\hline Undisturbed sample & 0.12 & 0.8 & 11.32 & 39.23 & 21.98 \\
\hline $\begin{array}{l}\text { Disturbed sample (filed Density and } \\
\text { Moisture Content) }\end{array}$ & 1.78 & 9.22 & 130.41 & 166.71 & 93.41 \\
\hline Disturbed sample (MMD and OMC) & 1.35 & 7.07 & 100 & 178.48 & 100 \\
\hline
\end{tabular}

\subsubsection{Swelling Potential Tests for Lime Stabilized Samples}

For showing the influence of stabilization with lime on swelling properties of soil, swelling potential tests were conducted on stabilized samples with 2,4 and $6 \%$ of lime and curing time of 7, 14, 21 and 28 days.

By analyzing the obtained results of swelling potential of lime stabilized samples, it could be concluded that stabilization of mentioned soil with lime is efficient and reduces free swelling and swelling pressure of soil in nonstabilized state. As observed, with adding lime to the saline soil, free swelling has been reduced by $7-22 \%$ and swelling pressure reduced by 15-33\% for stabilized samples by lime in different curing time that shows the stabilization of soil with lime is favorable. Figures 10 and 11 exhibit the effect of lime on free swelling and swelling pressure. 


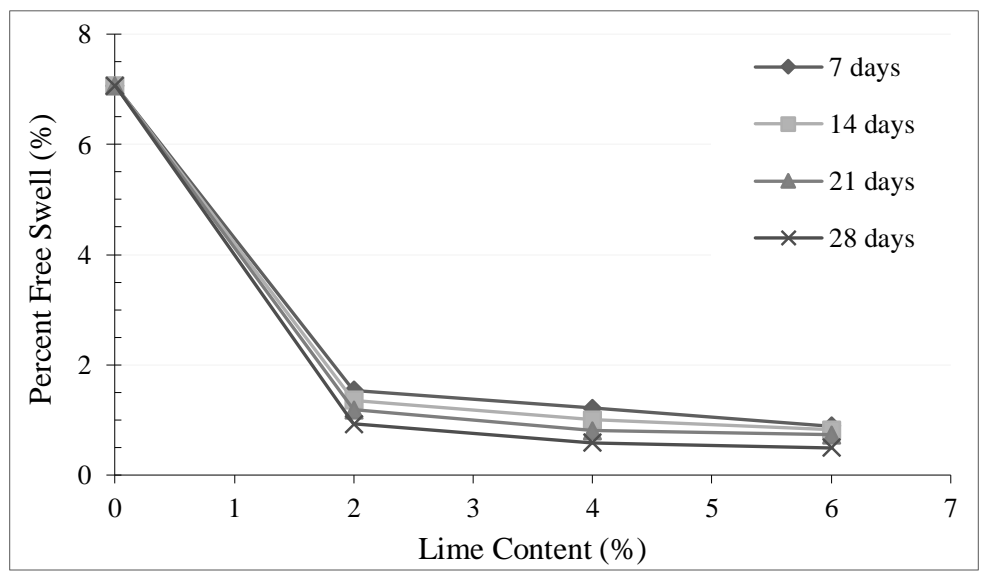

Figure 10. The effect of lime on free swelling of saline soil

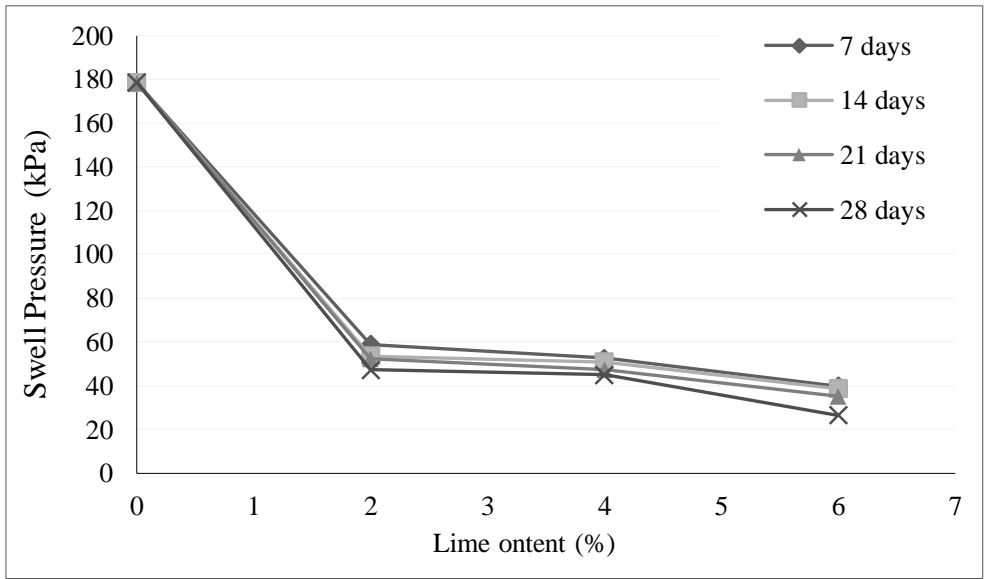

Figure 11. The effect of lime on swelling pressure of saline soil

\subsubsection{Swelling Potential Tests on Polymer Stabilized Samples}

Based on analyzing obtained results of free swelling test and swelling pressure determination tests on stabilized samples in abovementioned condition, one could conclude that stabilization of studied soil with polymer is effective and considerably reduces free swelling of soil in non-stabilized state. As observed in previous sections, with adding polymer to saline soil, free swelling reduces by $70-87 \%$ that is much favorable; but, swelling pressure decreases from $44 \%$ to $12 \%$. Increase of different polymer content with different curing time varies with respect to natural soil. The cause of swelling pressure of stabilized soil with polymer, in spite of reducing free swelling, is because of this fact that stabilized soil after presence of water and beginning of free swelling during chemical reactions that take place between soil and polymer becomes more rigid and solid and for returning to initial state (reach zero free swelling) it requires more exerting pressure.

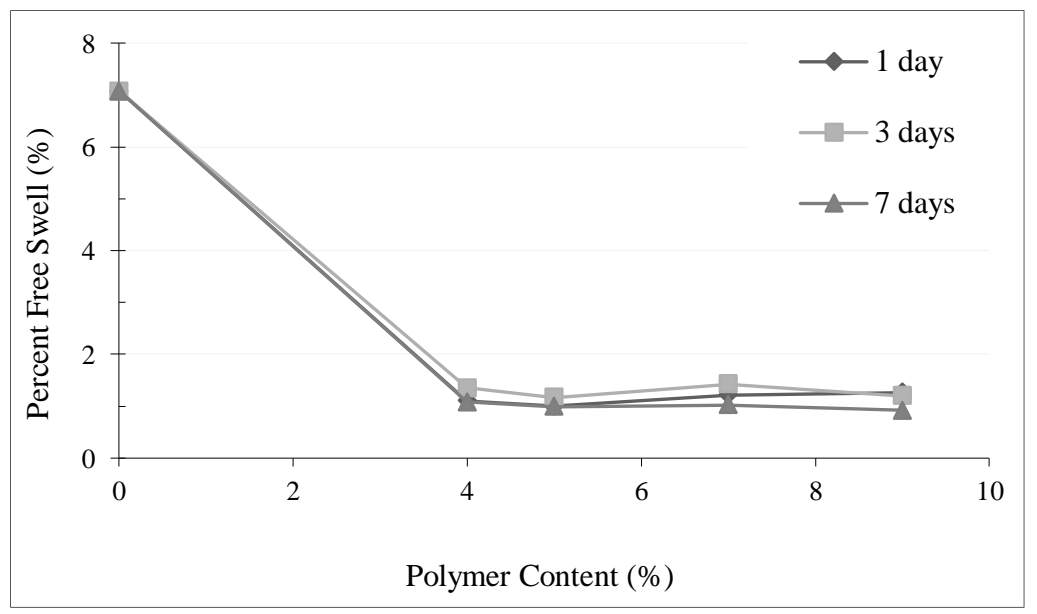

Figure 12. The effect of polymer on free swelling pressure of saline studied soil 


\subsubsection{Swelling Potential Test on Polypropylene Fiber Reinforced Samples}

For showing the effect of polypropylene fiber reinforcement of studied soil, swelling potential tests were conducted on reinforced samples with $0.1,0.2,0.3$ and $0.4 \%$ of polypropylene fiber. Obtained results are shown in Table 6.

Table 6. Results of swelling potential tests on polypropylene fiber reinforced samples

\begin{tabular}{ccccc}
\hline $\begin{array}{c}\text { Polypropylene } \\
\text { fiber content }(\boldsymbol{\%})\end{array}$ & Free swelling $(\boldsymbol{\%})$ & $\begin{array}{c}\text { Free normalized swelling of } \\
\text { disturbed sample* }(\boldsymbol{\%})\end{array}$ & $\begin{array}{c}\text { Swelling } \\
\text { pressure (kPa) }\end{array}$ & $\begin{array}{c}\text { Swelling pressure of } \\
\text { disturbed sample* }(\%)\end{array}$ \\
\hline 0.1 & 2.74 & 38.76 & 50.01 & 28.02 \\
0.2 & 1.64 & 23.20 & 33.34 & 18.58 \\
0.3 & 2.21 & 31.26 & 44.13 & 24.73 \\
0.4 & 3.24 & 45.83 & 49.03 & 27.47 \\
\hline
\end{tabular}

*Reconstructed sample with natural soil with maximum dry density and optimal moisture content

According to above results, it can be concluded that, reinforcement of soil with polypropylene fiber is effective and reduces free swelling and swelling pressure of soil in non-stabilized soil considerably. With summarizing results of free swelling tests on polypropylene fiber reinforced samples, one could depict free swelling percent with respect to polypropylene fiber of reinforced samples with different amounts of polypropylene fiber that is shown in Figure 13.

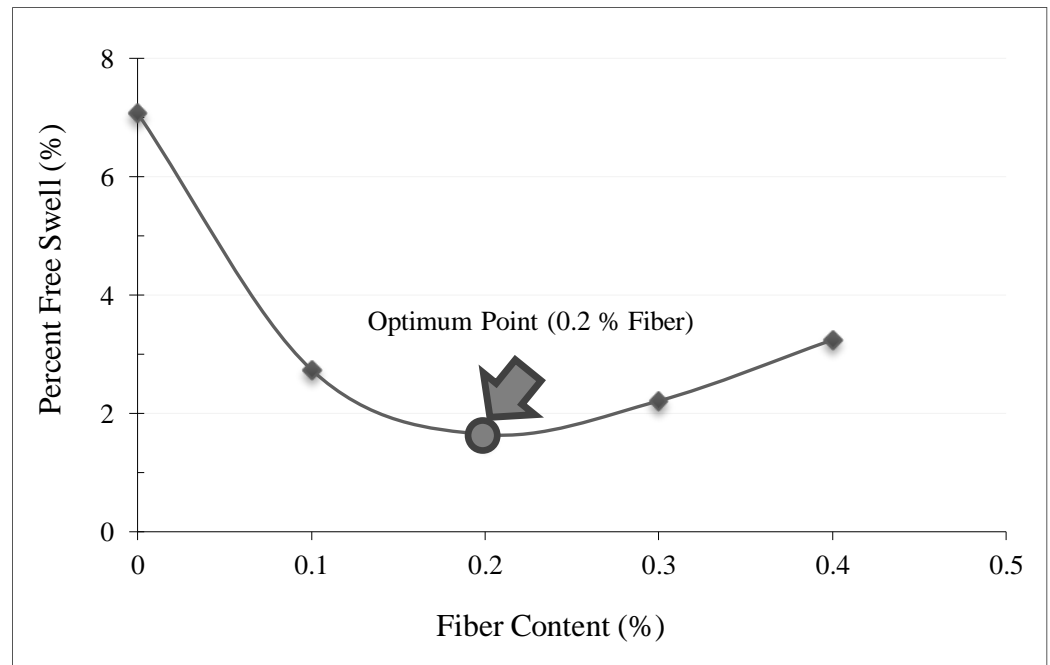

Figure 13. Free swelling percent vs. amount of polypropylene fiber for polypropylene fiberreinforced samples

As noted earlier, besides reducing free swelling, swelling pressure of reinforced sample has been reduced by $19-28$ $\%$. Swelling pressure curve vs. amount of polypropylene fiber has been shown in Figure 14.

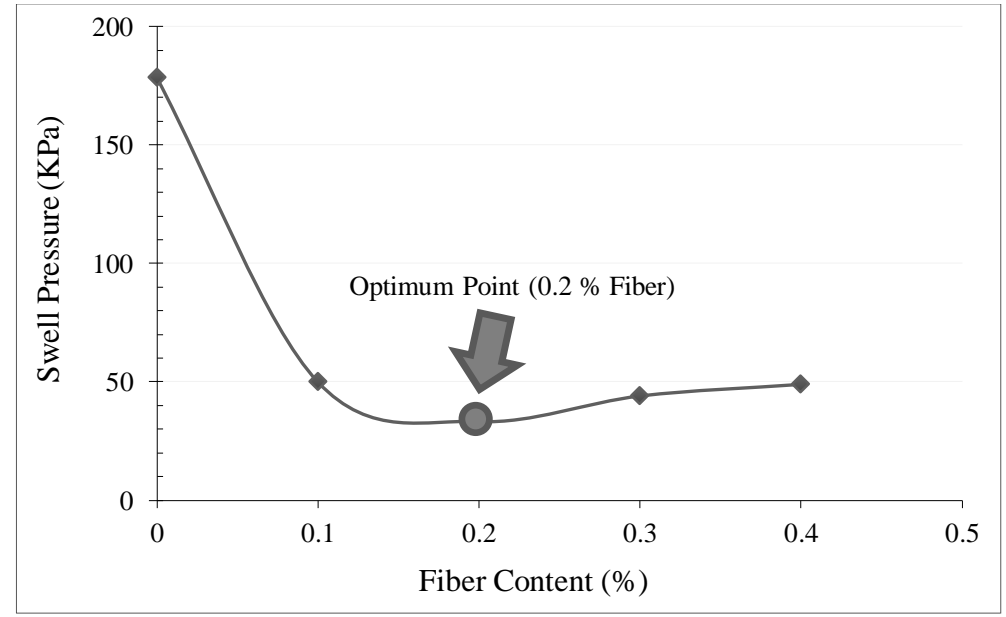

Figure 14. Swelling pressure curve vs. polypropylene fiber content 


\subsection{Consolidation Tests}

According to ASTM D2435 standard, consolidation test has been done. In this study the samples with $75 \mathrm{~mm}$ in diameter and height of $20 \mathrm{~mm}$ were used.

Consolidation test is followed by swelling potential test and providing saturation of sample is conducted. With regard to the fact that, swelling potential tests cycle on studied samples take 2 weeks, one could argue that most samples are saturated during these two weeks, but for the assurance of saturation, after free swelling sample has been weighed and due to height change of free swelling, the degree of saturation has been computed and saturation consolidation test has been conducted.

Results of consolidation test consist of three parts. In the first part, the result of this test on disturbed and undisturbed samples of the soil will be discussed. In the second part, the results of lime stabilized samples, and finally, results of polypropylene fiber reinforced sample are discussed. It should be noted that, the consolidation test of stabilized samples with polymer was impossible because of saturation.

For the determination of consolidation coefficient Square root of time fitting method was used. Considering the fact that consolidation parameters such as consolidation coefficient $\left(\mathrm{C}_{\mathrm{v}}\right)$, volume change coefficient $\left(\mathrm{m}_{\mathrm{v}}\right)$, compressibility factor $\left(\mathrm{a}_{\mathrm{v}}\right)$ and permeability factor $(\mathrm{K})$ vary during consolidation test, and at different pressures, reported values of this study are the average of obtained values at stress range of 100-200 kPa. This range has been selected with regard to exerting pressure of road loading over soil. For the determination of over-consolidation pressure $\left(\mathrm{P}_{c}\right)$, Casagrande depiction method (1936) curve was used on pressure- porosity.

Consolidation parameters obtained by consolidation test for three states are presented in Table 9. Based on the results of this table, one could conclude that, due to disturbance, consolidation coefficient has been increased and elasticity module and over-consolidation pressure have been decreased.

Table 9. Consolidation parameters of natural soil

\begin{tabular}{|c|c|c|c|c|}
\hline Consolidation parameters & Symbol & $\begin{array}{l}\text { Undisturbed } \\
\text { sample }\end{array}$ & $\begin{array}{c}\text { Disturbed sample (filed } \\
\text { Density and Moisture Content) }\end{array}$ & $\begin{array}{l}\text { Disturbed sample } \\
\text { (MMD and OMC) }\end{array}$ \\
\hline Over-consolidation pressure $(\mathrm{kPa})$ & $\mathrm{P}_{\mathrm{c}}$ & 183 & 110 & 168 \\
\hline Compression index & $\mathrm{c}_{\mathrm{c}}$ & 0.091 & 0.134 & 0.182 \\
\hline Swell index & $c_{\mathrm{s}}$ & 0.012 & 0.023 & 0.013 \\
\hline Recompression index & $\mathrm{c}_{\mathrm{r}}$ & 0.020 & 0.045 & 0.031 \\
\hline Coefficient of Consolidation $\left(\mathrm{cm}^{2} / \mathrm{sec}\right)$ & $c_{v}$ & $4.48 \mathrm{e}-4$ & $6.43 \mathrm{e}-4$ & $6.06 \mathrm{e}-4$ \\
\hline Coefficient of volume change $\left(\mathrm{cm}^{2} / \mathrm{kg}\right)$ & $\mathrm{m}_{\mathrm{v}}$ & 0.013 & 0.033 & 0.024 \\
\hline Coefficient of compressibility $\left(\mathrm{cm}^{2} / \mathrm{kg}\right)$ & $a_{v}$ & 0.020 & 0.053 & 0.039 \\
\hline Coefficient of permeability $(\mathrm{cm} / \mathrm{sec})$ & $\mathrm{k}$ & $0.58 \mathrm{e}-8$ & $2.1 \mathrm{e}-8$ & $1.4 \mathrm{e}-8$ \\
\hline Young's modulus $\left(\mathrm{kg} / \mathrm{cm}^{2}\right)$ & $\mathrm{E}$ & 100.79 & 37.46 & 51.63 \\
\hline
\end{tabular}

\subsection{Investigating the Behavior of U-Lnp' from the Results of Consolidation Experiments for the Studied Soil}

In the present study, the main purpose of this experiment is to study the variation of the stress path in the U-Lnp' space. For investigating stress path, the changes of saline soil in compaction standard test of three different states (undisturbed, reconstructed disturbed sample with in situ moisture content and density and reconstructed disturbed sample with maximum dry density and optimal moisture content) were used.

\subsubsection{Effect of the Disturbance on the Behavior of U-Lnp'}

For the comparing and showing the effect of the disturbance, $U \sigma^{\prime} \sigma_{v}^{\prime}$ and $\sigma$ 'h, are measured during the experiment. ULnp' curves are depicted for both cases is shown in Table 10 and Figure 15. As could be observed from Figure, the disturbance leads to the increase of consolidation settlement and changes in the slope of the normal consolidation line $\lambda$ and the slope of the inflation line $\kappa$. According to this figure, soil disruption has a significant effect on increasing the slope of the normal consolidation line $\lambda$.

Accordingly due to the increase in the strength of the collision, changes in the slope of the normal consolidation line $\lambda$ and the slope of the inflation line $\kappa$ are observed. 
Table 10. Loading chart for undisturbed and disturbed samples

\begin{tabular}{|c|c|c|c|c|c|c|c|c|}
\hline \multirow{2}{*}{$\mathbf{P}(\mathbf{N})$} & \multirow{2}{*}{$\log p$} & \multirow{2}{*}{$p^{\prime}=(1 / 3) * \sigma^{\prime} v\left(1+2 K_{0}\right)$} & \multirow{2}{*}{$q^{\prime}=\sigma^{\prime} v\left(1-K_{0}\right)$} & \multirow{2}{*}{$\operatorname{Ln} \mathbf{P}^{\prime}$} & \multicolumn{2}{|c|}{ Undisturbed sample } & \multicolumn{2}{|c|}{ Disturbed sample } \\
\hline & & & & & $\mathbf{e}$ & $\mathrm{U}=\mathrm{e}+\mathbf{1}$ & $\mathbf{e}$ & $\mathrm{U}=\mathrm{e}+\mathbf{1}$ \\
\hline 24.3206 & 1.3860 & 23.5099 & 1.2160 & 3.1574 & 0.5289 & 1.5363 & 0.5684 & 1.5684 \\
\hline 48.7393 & 1.6879 & 47.1147 & 2.4370 & 3.8526 & 0.5207 & 1.5275 & 0.5412 & 1.5412 \\
\hline 97.3805 & 1.9885 & 94.1345 & 4.8690 & 4.5447 & 0.5100 & 1.5160 & 0.5109 & 1.5109 \\
\hline 194.8591 & 2.2897 & 188.3638 & 9.7430 & 5.2384 & 0.4985 & 1.5023 & 0.4722 & 1.4722 \\
\hline 389.6202 & 2.5906 & 376.6329 & 19.4810 & 5.9313 & 0.4860 & 1.4860 & 0.4330 & 1.4330 \\
\hline 194.8591 & 2.2897 & 188.3638 & 9.7430 & 5.2384 & 0.4889 & 1.4912 & 0.4376 & 1.4376 \\
\hline 97.3805 & 1.9885 & 94.1345 & 4.8690 & 4.5447 & 0.4926 & 1.4938 & 0.4434 & 1.4434 \\
\hline 48.7393 & 1.6879 & 47.1147 & 2.4370 & 3.8526 & 0.4964 & 1.4974 & 0.4516 & 1.4516 \\
\hline 24.3206 & 1.3860 & 23.5099 & 1.2160 & 3.1574 & 0.4994 & 1.5008 & 0.4566 & 1.4566 \\
\hline 48.7393 & 1.6879 & 47.1147 & 2.4370 & 3.8526 & 0.4993 & 1.5020 & 0.4546 & 1.4546 \\
\hline 97.3805 & 1.9885 & 94.1345 & 4.8690 & 4.5447 & 0.4964 & 1.4994 & 0.4493 & 1.4493 \\
\hline 194.8591 & 2.2897 & 188.3638 & 9.7430 & 5.2384 & 0.4915 & 1.4938 & 0.4407 & 1.4407 \\
\hline 389.6202 & 2.5906 & 376.6329 & 19.4810 & 5.9313 & 0.4852 & 1.4850 & 0.4259 & 1.4259 \\
\hline 779.2404 & 2.8917 & 753.2657 & 38.9620 & 6.6244 & 0.4697 & 1.4635 & 0.3831 & 1.3831 \\
\hline
\end{tabular}

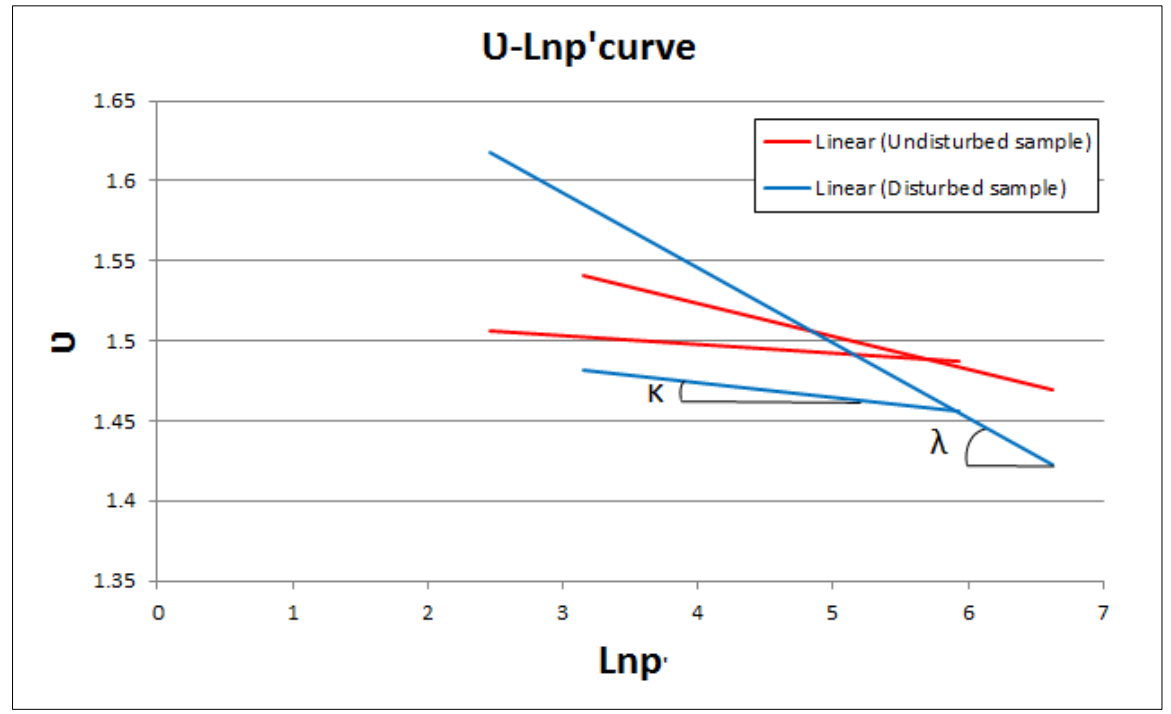

Figure 15. Effect of disturbance on U-Lnp'curve

\subsubsection{The Effect of Stabilizing with Lime on the Behavior of U-Lnp'}

For conducting consolidation test on lime stabilized samples, samples with optimal moisture content and maximum dry density obtained by results of compaction standard test, were constructed on saline soil with 2, 4 and $6 \%$ of lime. Thereafter, for curing time (7, 14, 21 and 28 days), samples were kept in plastic bags; then set into odometer apparatus and after saturation and free swelling, consolidation test is done. In order to compare the effect of lime on the slope of the normal consolidation line $\lambda$, Figure 16 shows the slope of the normal consolidation line vs. the amount of lime at different processing times, which is normalized to normal slope of soil in normal conditions. As it is obvious in this figure, addition of lime to the saline soil leads to the decrease of normal consolidate line slope $\lambda$ whose rate is reduced with the addition of lime for different curing time. This decrease is a result of lime setting with soil and strength of sample against settlement that this strength will be more with the increase of lime amount and also curing time, and consequently slope of initial loading curve will be reduced. According to this curve, it is obvious that slope of normal consolidate line of soil with addition of 2, 4 and $6 \%$ of lime for curing time of 7 days have been decreased by 28,49 and $67 \%$ respectively in comparison with non-stabilized state. Considerable decrease of soil settlement with addition of lime is indicated. 


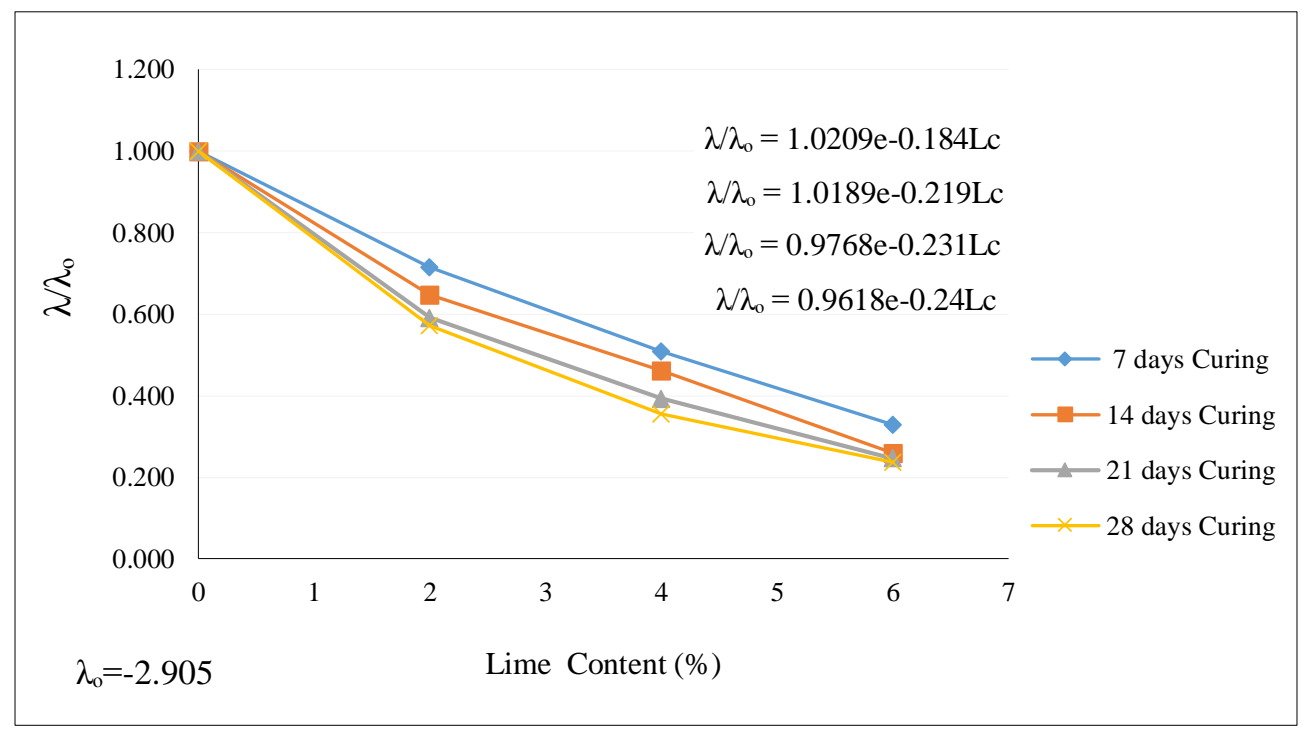

Figure 16. Effect of lime on the slope of normal soil consolidation in the normalized form

For studying the effect of lime on swell line slope к, Figure 17 shows swell line slope with respect to the amount of added lime that has been normalized relative to swell line slope of natural soil at experimental compaction state. As it is obvious in this figure, addition of lime to saline studied soil leads to the decrease of swell line slope and its rate decreases with the addition of lime for different curing time. According to the figure, it is obvious that swell line slope of soil with addition of 2, 4 and $6 \%$ of lime respectively for curing time of 7 days have decreased by 20,34 and $42 \%$ relative to non-stabilized state.

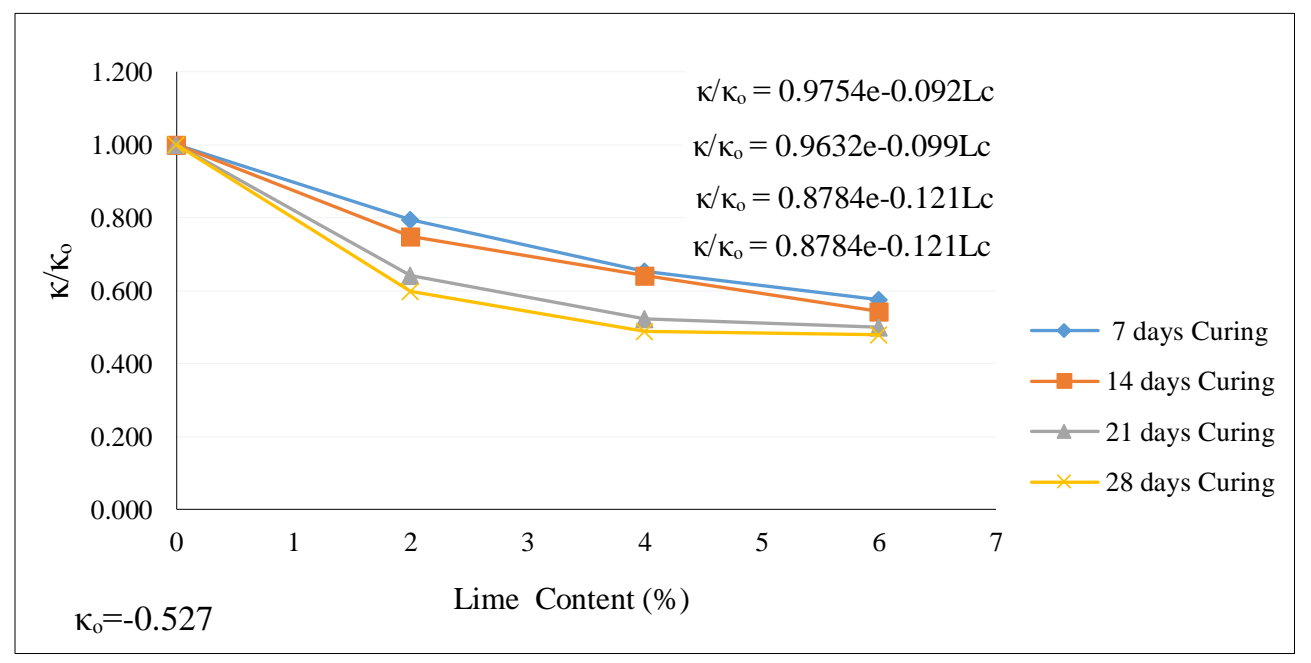

Figure 17. Effect of lime on the slope of the soil swelling line in the normalized form

\subsubsection{The Impact of Polypropylene Fiber on the Behavior of U-Lnp'}

For conducting consolidation test on polypropylene fiber reinforced samples, samples with optimal moisture content and maximum dry density obtained from results of compaction test were constructed on saline soil samples with 0.1 , $0.2,0.3$ and $0.4 \%$ of polypropylene fiber. Thereafter samples were placed into odometer test apparatus and after saturation and free swelling consolidation test was done.

For a better evaluation, the effect of polypropylene fiber on normal consolidate line slope $\lambda$, Figure 18 shows normal consolidate line slope with respect to the amount of polypropylene fiber that has been normalized relative to normal consolidate line slope of natural soil.

As it could be observed form figure, adding polypropylene fiber to saline studied soil leads to the significant decrease of normal consolidate line slope $\lambda$ whose rate with the increase of polypropylene fiber will be constant until it reaches $0.2 \%$ and increases from 0.2 to 0.4 . These increases are due to the enhancement of permeability, and as a consequence the increase of consolidation settlement. Therefore, the slope of initial loading curve will increase. With regard to this curve, it could be observed that normal consolidate line slope of soil with adding $0.1,0.2,0.3$ and 0.4 percentage of polypropylene fiber, is reduced by about $98 \%$ in comparison with the non-stabilized state. 


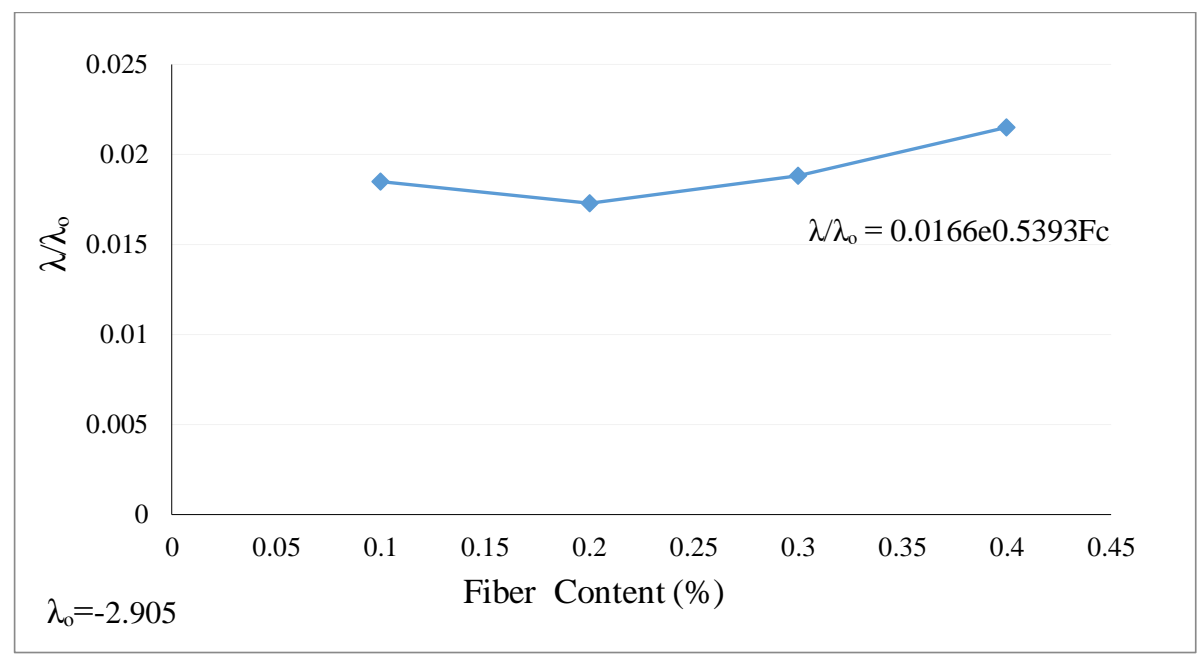

Figure 18. Effect of polypropylene fibers on soil slope of the normal consolidation line in the normalized form

For the comparison of the effect of polypropylene fiber on swell line slope к, Figure 19 shows swell line slope curve vs. the amount of polypropylene fiber, and it has been normalized at experimental compaction state in comparison to swell line slope of natural soil. As it could be observed form figure, adding polypropylene fiber to saline studied soil leads to the reduction of the swell line slope, which decreases its rate of decrease by increasing the polypropylene fiber. Based on this curve, it could be observed that swell line slope of soil has declined by about $97 \%$ via adding $0.1,0.2,0.3$ and 0.4 percentage of polypropylene fiber.

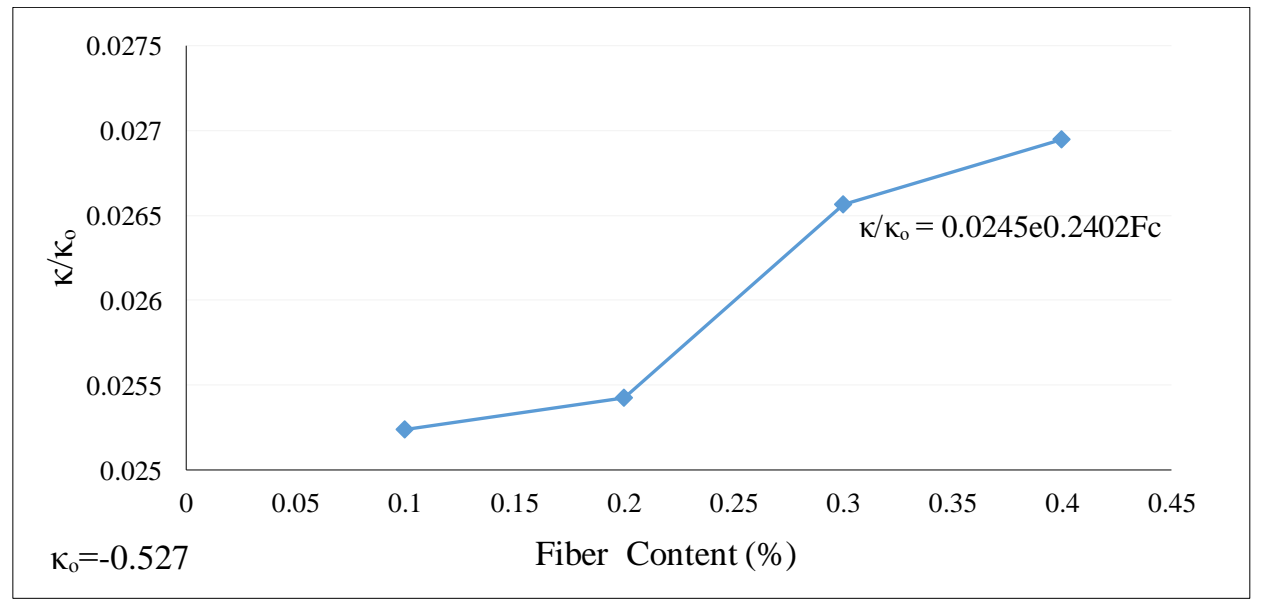

Figure 19. The effect of polypropylene fiber on the slope of the soil swelling line in normalized form

\section{Conclusions}

In this study the results of experimental investigations on volume change behavior of a saline soil as disturbed, undisturbed and lime stabilized and polymer and polypropylene fiber reinforced have been presented. According to the conducted tests one could conclude the following results:

- According to the results of swelling tests, one could conclude that the main cause of swelling of the soil is disturbance and initial composition and structure destruction.

- By conducting consolidation tests on disturbed samples and undisturbed samples, it can be observed that disturbance causes more consolidation settlement and it also will increase normal consolidate line slope $(\lambda)$ curve. Despite higher density of reconstructed sample, in initial loading, this sample experienced more consolidation settlement than constructed sample with optimal moisture content and maximum dry density.

- Adding lime, polymer and polypropylene fiber to soil causes the decrease of liquid limit of the soil, but this decrease is more by lime and polymer in comparison with polypropylene fiber.

- Comparison between swelling parameters (free swelling and swelling pressure) of polymer and lime stabilized samples and reinforced samples with polypropylene fiber showed that all of them decrease free swelling, but about swelling pressure for the studied soil, $9 \%$ of polymer leads to an increase and in other cases leads to the decrease of swelling pressure. This fact is a disadvantage of stabilization with polymer. 
- Comparison between setting time of stabilized samples with lime and polymer shows that setting time of polymer is very fast relative to lime in a way that polymer in all conditions in one day swells more than $70 \%$ freely, whereas lime, after 7 days, swells $70 \%$ of free swelling.

- Comparison among consolidation parameters of stabilized samples with lime and polymer and reinforced samples with polypropylene fiber showed that the slope of the normal consolidation line $(\lambda)$ and the swell line ( $\kappa)$ in limestabilized samples and fiber-reinforced specimens polypropylene fiber is reduced, which is a very significant decrease in polymer-based arsenal samples, but lime increases elasticity module and all other cases lead to its decrease. This fact is one of the disadvantages of polypropylene fiber stabilization with.

- Regarding the negative aspects for using polymer and stabilized samples with polypropylene fiber relative to lime, it appears that although lime is a traditional stabilizer, but is still more suitable for most of the projects and the use of polymer due to its rapid fastening is recommended only in certain projects.

\section{References}

[1] AL-Shamrani, Mosleh A. "Applicability of the rectangular hyperbolic method to settlement predictions of sabkha soils." Geotechnical and Geological Engineering 22, no.4 (2004): 563-587. doi: 10.1023/B:GEGE.0000047046.73649.04.

[2] Al-Homidy, Abdullah A. Dahim, Mohammed H. Abd El Aal, Ahmed K. "Improvement of geotechnical properties of sabkha soil utilizing cement kiln dust." Journal of Rock Mechanics and Geotechnical Engineering 9, no.4 (2017): 749- 760. doi: 10.1016/j.jrmge.2016.11.012.

[3] Chen, F.H. Foundations on Expansive Soils. 1st edition. Elsevier, 1988.

[4] Likos, W.J, "Measurement of crystalline swelling in expansive clay." Geotechnical Testing Journal 27, no. 6 (2004):1. doi: $10.1520 /$ GTJ11857.

[5] Sherif, M.A. Ishibashi, I. Medhin, B.W. ASCE, Journal of the Geotechnical Engineering Division 108, no.1 (2004): 33 - 45.

[6] Jones, D.E. "Expansive soils and housing development." in proceedings of Workshop on Expansive Clays and Shale in Highway Design and Construction, 1973.

[7] Aiban, S. A. Al-Ahmadi, H.M. "Effect of geotextile and cement on the performance of sabkha subgrade." Building and Environment 41, no.6 (2006): 807-820. doi: 10.1016/j.buildenv.2005.03.006.

[8] El Sharif, M. Abdel Aziz, Mahmoud M. Abu Zeid, Mahmoud Ali Mahmoud. Walaa M, Shahat. "Effect of Cement Kiln Dust on the Engineering Properties of Sabkha Soil." International Journal of Engineering Science and Computing 7, no. 10 (2017): 1520615210 .

[9] Haidari, S. "Stabilization of saline soils using lime and microsilica." Master's thesis, International University of Imam Khomeini, Department of Technical and Engineering, 2009.

[10] Rajasekaran, G. Narasimha Rao, S. “Compressibility behaviour of lime-treated marine clay.” Ocean Engineering 29, no.5 (2002): 545-559. doi: 10.1016/S0029-8018(01)00010-5.

[11] Al-Khashab, Mohammad Natheer. Al-Hayalee, Mohammed Thafer. "Stabilization of Expansive Clayey Soil Modified by Lime with an Emulsified Asphalt Addition.” Eng. \& Technology 26, no.10 (2008).

[12] Sakr, Mohamed A. Shahin, Mohamed A. Metwally, Yasser M. "Utilization of Lime for Stabilizing Soft Clay Soil of High Organic Content." GeotechGeolEng 27, no.1 (2009): 105-113. doi: 10.1007/s10706-008-9215-2.

[13] Fang, HSAI-Yang. Foundation engineering handbook. The Chapman \& Hall, 1991.

[14] Kariuki, P.C. Meer, F. “A unified swelling potential index for expansive soils.” Journal of Engineering Geology 72, (2004):1-8. doi: 10.1016/S0013-7952(03)00159-5.

[15] Abdi, Mahmoodreza. Ibrahimi, Ahadollah. "Effect of length and amount of polypropylene fiber on mechanical properties of Kaolinite.” K. N. Toosi University of Technology, Tehran.

[16] Samimifar, M. "Evaluation of shear strength parameters and stabilization of saline soil." Master's thesis, International University of Imam Khomeini, Department of Technical and Engineering.

[17] Banulkizler, S. Aytekin, Mustafa. Türker, Emel. Yavuz, Halil İbrahim. "Effect of fibers on swelling characteristics of bentonite." 2nd International Conference on New Developments in Soil Mechanics and Geotechnical Engineering, Near East University, Nicosia, North Cyprus, 2009. 